\title{
Erratum to: High impact strategy research by overseas Chinese scholars in leading business journals: 1991-2011
}

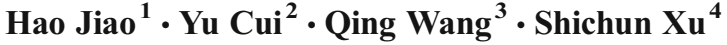

Published online: 30 July 2015

(C) Springer Science+Business Media New York 2015

\section{Erratum to: Asia Pac J Manag \\ DOI 10.1007/s10490-014-9392-x}

Following the on-line publication of the above article several errors have come to light that require clarification in the form of an erratum.

First, table 1 identifies Gilad Chen (University of Maryland) as the $27^{\text {th }}$ highest impact overseas Chinese strategy scholar. This is an error. Professor Chen is not primarily a strategy scholar nor can he be categorized as an overseas Chinese individual. In the revised manuscript, it is available from the editor-in-chief. Gilad Chen has been removed from Tables 1, 3, and 4 .

Second, we misidentified or misspelled the institutional affiliations of the following.

\#24 XiaoweiLuo in Table 1 should be Xiaowei Luo (add a space) and the affiliation should be "INSEAD" (not "University of Illinois"). In Tables 3 and 4, Xiaowei Luo's affiliation should be "INSEAD" too. \#4 Eric W. K. Tsang in Table 4, should be "U of Texas at Dallas" (not "U of Texas"). \#11 Yi Jiang in Table 4, should be "California State University at East Bay" (not "Calif. State U."). \#12 Zhiang

The online version of the original article can be found at http://dx.doi.org/10.1007/s10490-014-9392-x.

Yu Cui

cuiyu@bistu.edu.cn

Hao Jiao

haojiao@bnu.edu.cn

1 Business School, Beijing Normal University, No. 19, Xin Jie Kou Wai Street, Beijing, China 100875

2 School of Economics \& Management, Beijing Information Science \& Technology University, Beijing, China

3 School of Government, Beijing Normal University, Beijing, China

4 Department of Marketing \& Supply Chain Management, University of Tennessee, Knoxville, TN, USA 
(John) Lin in Table 4, should be "U of Texas at Dallas" (not "U of Texas"). \#28 Peter Ping Li in Table 4, should be "Copenhagen Business School" (not "California State University at Stanislaus"). 